\title{
Expression of metalloproteinases and their tissue inhibitors in squamous cell laryngeal carcinoma
}

\author{
T.A. CHRISTOPOULOS ${ }^{1}$, N. PAPAGEORGAKOPOULOU ${ }^{1}$, P. RAVAZOULA ${ }^{2}$, \\ N.S. MASTRONIKOLIS ${ }^{3}$, T.A.PAPADAS ${ }^{3}$, D.A. THEOCHARIS ${ }^{4}$ and D.H. VYNIOS ${ }^{1}$ \\ ${ }^{1}$ Laboratory of Biochemistry, Department of Chemistry; ${ }^{2}$ Department of Pathology, University Hospital; \\ ${ }^{3}$ H.N.O. Clinic, University Hospital, Department of Medicine, and ${ }^{4}$ Laboratory of Biological Chemistry, \\ Department of Medicine, University of Patras, 26500 Patras, Greece
}

Received January 5, 2007; Accepted June 8, 2007

\begin{abstract}
The hallmark of cancer invasion is the degradation of extracellular matrix components. Matrix metalloproteinases are the major enzymes participating in this event and their activity is regulated extracellularly by their presence as proenzymes and the concomitant presence of the specific tissue inhibitors. The present study describes the immunohistochemical localization of gelatinases, matrix metalloproteinase (MMP)-2 and -9 and tissue inhibitor of metalloproteinase (TIMP)-1 and -2 in human laryngeal carcinoma and their expression with respect to tumor classification and compared with the respective healthy subjects. MMP-2 was immunolocalized in the cytoplasm of the epithelial cells and in the loose connective tissue, whereas MMP-9 was also observed in basement membrane and chondrocytes. Both were also found in tumor cells, but staining was decreased with increasing stage of cancer. TIMP-1 was present exclusively in stroma and totally absent from tumor cells and it was overexpressed in normal cells surrounding the tumor. TIMP-2 was identified in the cytoplasm of epithelial cells, in stroma and sometimes in chondrocytes. In addition, it was present in tumor cells of only stage IV samples. The expression level of both gelatinases and TIMPs increased as the stage of cancer increased, suggesting the possible post-transcriptional removal of their mRNA. These observations, performed in a given head and neck site, suggest that the behavior of head and neck tumors seems to depend on the site and additional studies should be performed to obtain a general understanding of the disease and ascertain the role of the constituents examined.
\end{abstract}

Correspondence to: Dr D.H. Vynios, Laboratory of Biochemistry, Department of Chemistry, University of Patras, 26500 Patras, Greece

E-mail: vynios@chemistry.upatras.gr

Key words: cancer, extracellular matrix, enzymes, enzyme inhibitors, gelatinases, metalloproteinases, matrix metalloproteinases, tissue inhibitors of metalloproteinases

\section{Introduction}

Squamous cell carcinomas (SCCs) of the head and neck are characterized by regional and distant metastases, through which the survival of the patients declines to $50 \%$ (1). Invasion is characterized by the degradation of the extracellular matrix (ECM) surrounding the tumor. Tumor cells penetrate the basement membrane and migrate through the interstitial stroma, while they are also able to penetrate vascular walls allowing metastasis to distant sites. ECM is degraded by various proteases, the matrix metalloproteinase (MMP) family having a pivotal role. These MMPs are aberrantly expressed in SCCs of the head and neck (2), as well as in most malignant tumors, and play a significant role in metastasis.

The proteinases involved in this process are gelatinase- $\mathrm{A}$ and -B (MMP-2 and -9), stromelysin-1, -2, -3 (MMP-3, -10, and -11), MMP-1, MT1-MMP (MMP-14) and collagenase-3 (MMP-13), MMP-2 and -9 being the main proteinases involved in tumor invasion (3). Most of the MMPs are expressed as zymogens and MMP-14 is thought to be the critical enzyme for at least gelatinase activation. The regulation of MMPs occurs as much at the transcriptional level as at the post-translational level. Their activities are controlled post-translationally in the extracellular space via the coordinated activation of secreted proenzymes as well as through their interaction with specific tissue inhibitors of metalloproteinases (TIMPs). Four TIMPs have been identified and characterized, with TIMP-1 and -2 being the predominant (4). TIMP is bound to active MMP at molar ratio 1:1 causing efficient inhibition of enzymatic activity. Gelatinases are unique among MMPs because of their ability to interact with TIMP in both the active and pro-enzyme form.

Numerous studies have implicated MMPs and especially gelatinases and the respective tissue inhibitors in SCC of the head and neck. It appears that MMPs are increased as compared to the normal state in both protein level and enzymatic activity. In addition, highly increased amounts of active enzymes have been observed, which are totally absent from healthy tissues. Active gelatinases have also been observed in biopsies of tissues positive for cancer, whereas the respective normal tissues were negative. It is not only gelatinases, but TIMPS also that are expressed differentially 
in cancer, the alteration of TIMP-2 being more significant, since it may participate in dual roles. TIMP-2 may act either as a part of the defensive mechanism of the host tissue or as a mechanism of activation of MMP-2 and MMP-13, through the complexation with MT1-MMP in the cell surface $(5,6)$. It is therefore interesting to have more information on the nature of cells that produce TIMPs to obtain a clear understanding of the mechanisms involved in cancer. Immunohistochemical analysis of laryngeal carcinoma has shown that MMPs and TIMPs are produced and secreted by both squamous cancer cells and stromal cells $(4,7-8)$. However they are predominantly produced by the peritumoral cells $(9,10)$.

In view of the observations that the analysis of gelatinases and TIMPs may aid diagnosis and/or prognosis in head and neck cancers (11-17), the aim of the present study was the investigation of their expression in healthy human laryngeal tissues and laryngeal squamous cell carcinoma of different stages of cancer, together with their respective localization in tissues.

\section{Materials and methods}

Materials. The polyclonal antibodies against MMP-2, MMP-9, TIMP-1 and TIMP-2 were purchased from Chemicon (USA). A total RNA extraction kit was obtained from NucleoSpin Macherey-Nagel and RT-PCR was performed using a Qiagen one-step RT-PCR kit. All other chemicals used throughout the study were of the best available analytical grade.

Human samples. Human laryngeal cartilage was obtained from larynx after total laryngectomy for laryngeal carcinoma. The patient population consisted exclusively of men with an age range of 55-72 years. The primary tumors were squamous cell carcinomas (SCC) of the larynx from 25 patients of different stages. Two specimens were obtained from each patient, one from the malignant part and the other from the adjacent normal part of tissue, and either was used directly or stored at $-70^{\circ} \mathrm{C}$. Six healthy larynx samples were also obtained after autopsy from men with an age range of 45 to 67 years. The study design had the approval of the Ethics Committee of the University Hospital of Patras, Greece, and informed consent was obtained from all patients entering the study.

Immunohistochemical staining of tissue sections. Paraffinembedded tissue sections $(5 \mu \mathrm{m})$ were deparaffinized and rehydrated through graded alcohols into distilled water. Endogenous peroxidase activity was quenched by immersion of the tissue sections in hydrogen peroxide $\left(3 \% \mathrm{v} / \mathrm{v} \mathrm{H}_{2} \mathrm{O}_{2}\right.$ in methanol) for $20 \mathrm{~min}$. All incubation steps, except where stated, were performed at room temperature. Nonspecific antibody binding was blocked by incubation with $2 \%(\mathrm{v} / \mathrm{v})$ BSA in TBS (TBS-BSA) for $20 \mathrm{~min}$. The sections were then incubated with the primary antibodies diluted (1:500) in TBS-BSA for $1 \mathrm{~h}$ at room temperature. The obtained antigenantibody complexes were visualized by 20 -min incubation at room temperature using biotinylated goat anti-rabbit antibody diluted 1:200 in TBS-BSA and the avidin-biotin peroxidase technique (Dakopatts) according to the manufacturer's instructions. The staining was developed using 3,3-diamino-
Table I. Nucleotide sequences of the primers used in RT-PCR experiments.

Type of primer Nucleotide sequence

Sense

$\begin{array}{ll}\text { MMP-2 } & \text { 5'-ATCCGTGGTGAGATCTTCTTCTT-3' } \\ \text { MMP-9 } & \text { 5'-TGCCATTTTCCATTCATCTTCCAA-3' } \\ \text { TIMP-1 } & \text { 5'-CCTTCTGCAATTCCGACCTCGTC-3' } \\ \text { TIMP-2 } & \text { 5'-TGGAAACGACATTTATGGCAACC-3' } \\ \text { GADPH } & \text { 5'-ACATCATCCCTGCCTCTACTGA-3' }\end{array}$

Antisense

MMP-2 5'-AGCCAGGATCCATTTTCTTCTT-3'

MMP-9 5'-CTGCGGTGTGGTGGTGGTT-3'

TIMP-1 5'-CGGGCAGGATTCAGGCTATCTGG-3'

TIMP-2 5'-ACAGGAGCCGTCACTTCTCTTGAT-3'

GADPH 5'-AGTGGGTETCGCTGTTGAAGTC-3'

benzidine (DAB)/hydrogen peroxide for up to $5 \mathrm{~min}$. A light nuclear counterstain was applied with hematoxylin.

RNA extraction and RT-PCR. Laryngeal specimens were pulverized in liquid nitrogen and subjected to total RNA extraction, using the Nucleospin extraction kit, as described by the manufacturer and treated with RNase-free DNase to remove contaminating genomic DNA. Strand cDNA was synthesized from $200 \mathrm{ng}$ of total RNA in $50 \mu \mathrm{l}$ reaction components for use with the one-step RT-PCR kit, according to the manufacturer's instructions. This reaction mixture contained in addition $1 \mu \mathrm{M}$ of the sense and antisense primers shown in Table I. The amplification was performed in a GeneAmp 2400 thermal cycler (Perkin-Elmer Co.) and the reaction profile used for all primer sets was $95^{\circ} \mathrm{C}$ for $10 \mathrm{~min}$ for the activation of HotStarTaq DNA polymerase and then 25-35 cycles, depending on the analysis, at $94^{\circ} \mathrm{C}$ for $30 \mathrm{sec}, 58^{\circ} \mathrm{C}$ for $1 \mathrm{~min}, 72^{\circ} \mathrm{C}$ for $1 \mathrm{~min}$ and $72^{\circ} \mathrm{C}$ for $10 \mathrm{~min}$ to finalize extension. The number of cycles was chosen so that reactions could be terminated during the linear phase of amplification. The reaction products were separated by electrophoresis in $2 \%(\mathrm{w} / \mathrm{v})$ agarose gels containing Gelstar Stain to visualize the amplified cDNA fragments under UV. The gels were then scanned and the bands were analyzed densitometrically. Quantitative differences between cDNA samples were normalized by including GAPDH in all experiments.

Statistical analysis. Normality of distribution of values was tested with the Kolmogorov-Smirnov test. Results were statistically analyzed using the unpaired t-test to detect differences between groups. $\mathrm{p}<0.05$ was regarded as statistically significant. For the statistical analysis, Origin Pro 7.5 SRO statistical software was used (Origin Lab Corporation, USA).

\section{Results}

Immunohistochemical studies of laryngeal tissues. We examined the distribution of MMP-2 and -9 and TIMP-1 and 


\section{Healthy $\quad$ S2 S3}

A

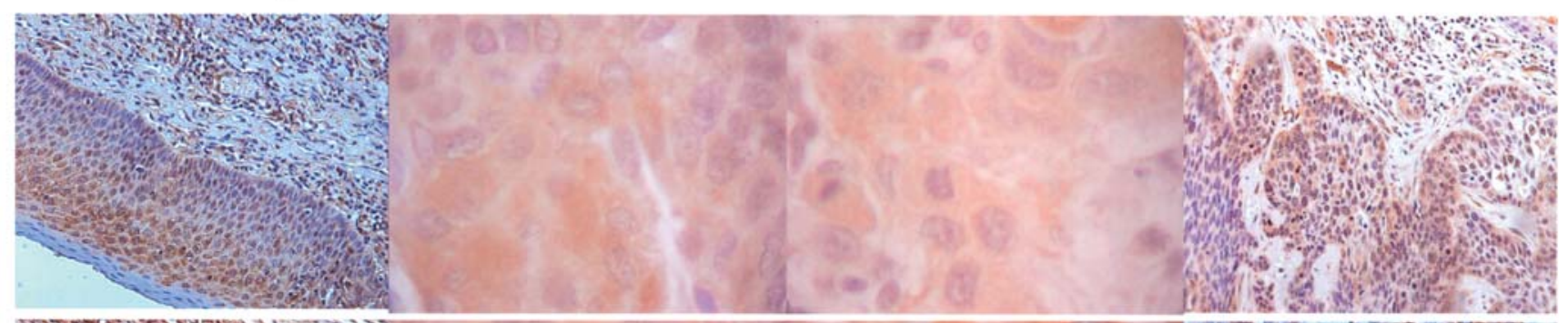

B

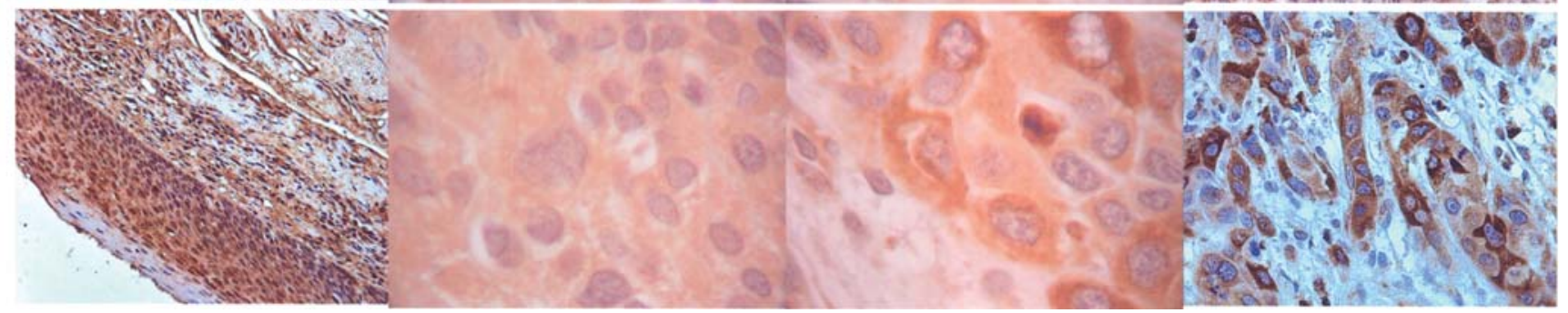

Figure 1. Representative images indicating the immunolocalization of MMP-2 (A) and MMP-9 (B) in healthy larynx and cancerous specimens of stages II to IV (S2, S3, S4, original magnification x400). Sections were stained using specific polyclonal antibodies against MMP-2 and MMP-9, respectively.

\section{Healthy}

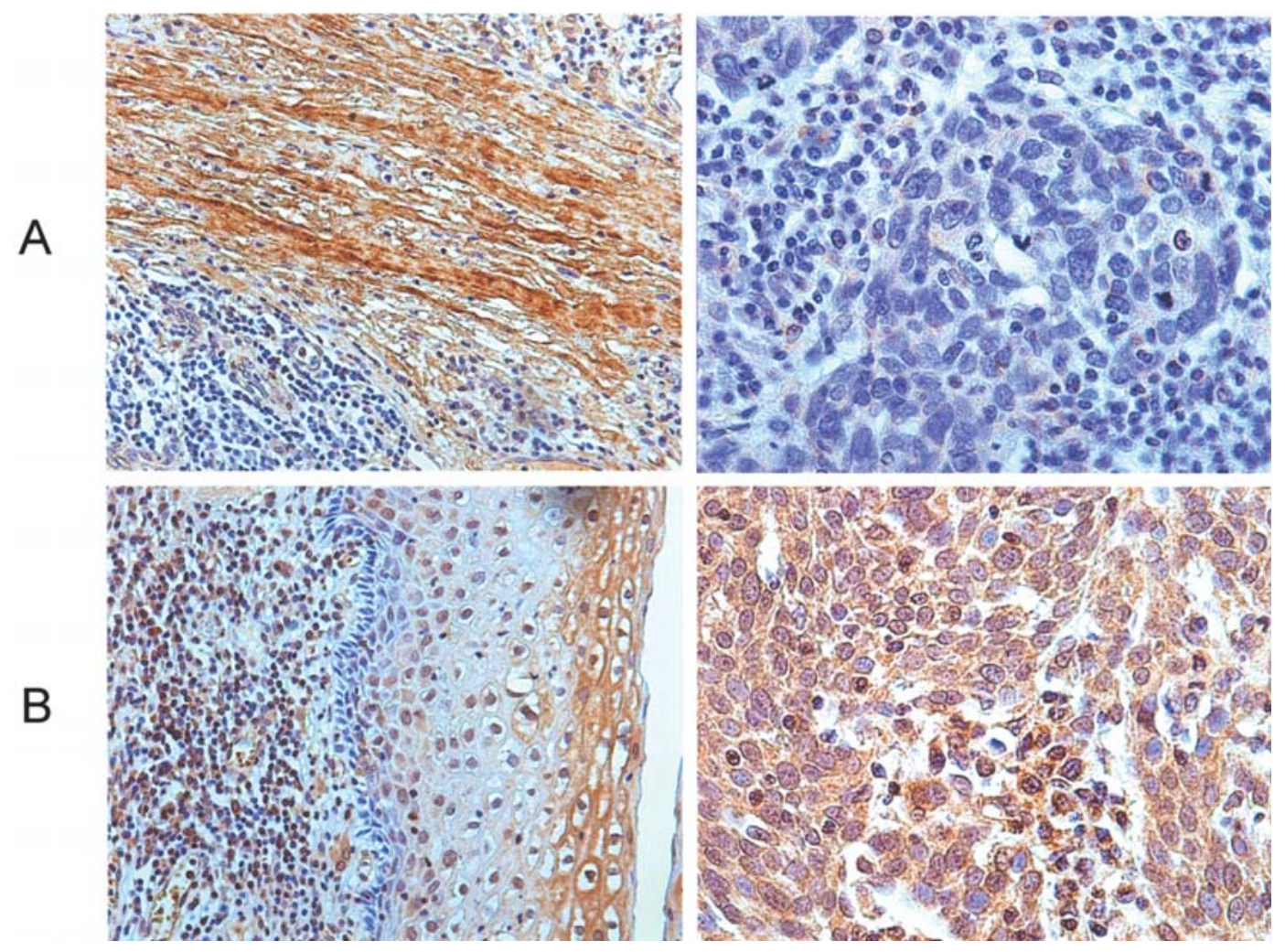

Figure 2. Representative images indicating the immunolocalization of TIMP-1 (A) and TIMP-2 (B) in healthy larynx and cancerous specimens of stage IV (S4, original magnification $\mathrm{x} 400$ ). Sections were stained using specific polyclonal antibodies against TIMP-1 and TIMP-2, respectively.

-2 in laryngeal specimens obtained after surgery, as well as in healthy subjects. The results obtained for MMP-2 are shown in Fig. 1A. This gelatinase was identified in healthy sections in the cytoplasm of the epithelial cells and in the loose connective tissue. It was absent in basement membrane and chondrocytes (Fig. 1, healthy). In cancerous sections, MMP-2 was found to be present in the tumor cells of all (5/5) stage II samples (Fig. 1, S2) and in most (4/6) of the stage III samples (Fig. 1, S3), whereas it was almost absent (1/5) in those of stage IV samples (Fig. 1, S4). MMP-2 staining was not related to grade. Similar results were obtained for MMP-9 (Fig. 1); it was present in tumor cells of all stage II samples $(5 / 5)$, in 

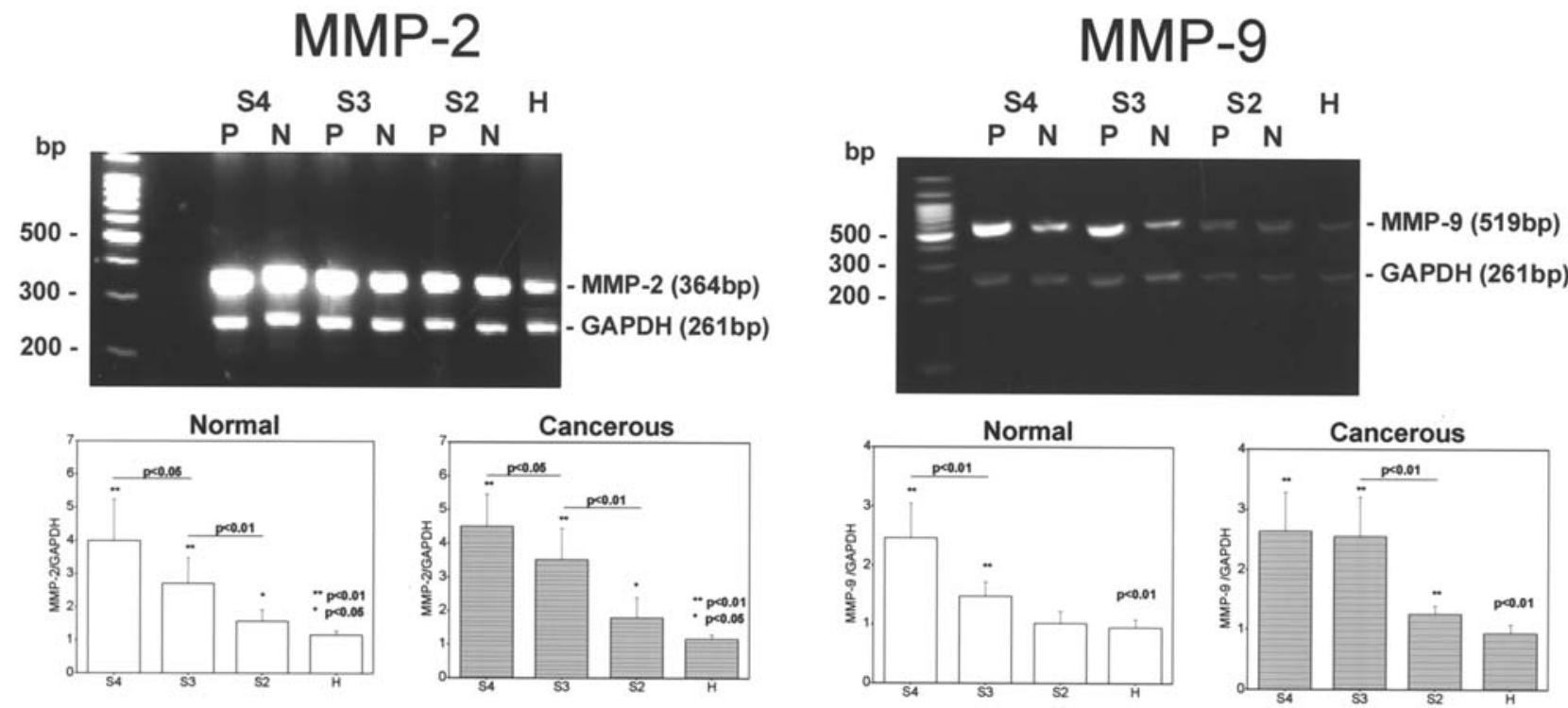

\section{TIMP-1}
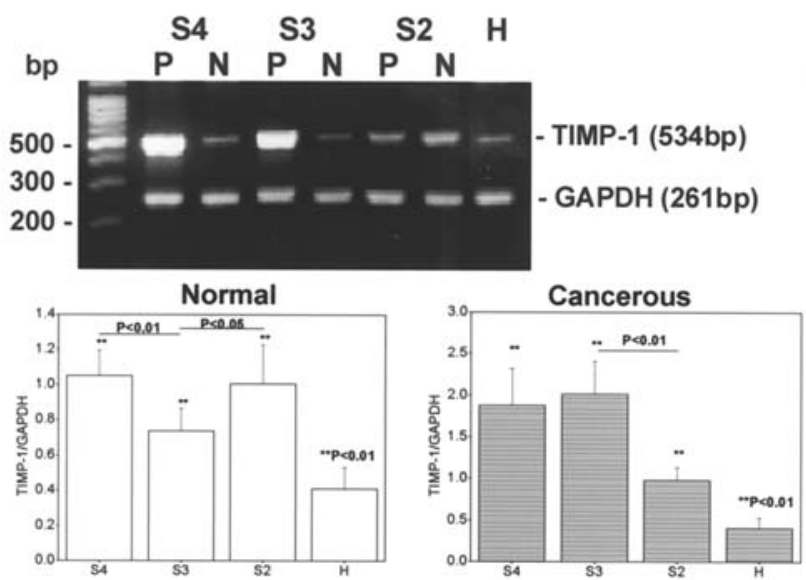
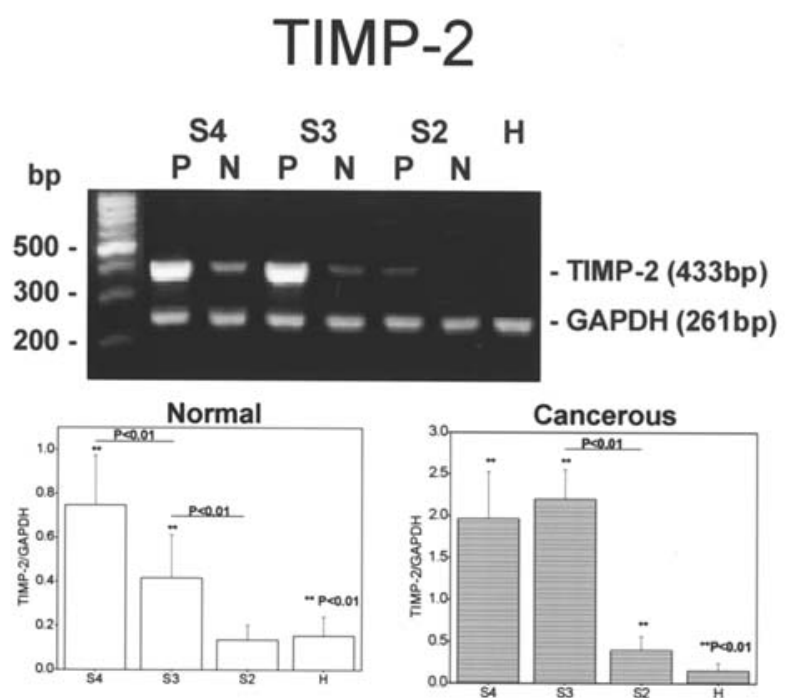

Figure 3. Representative data of expression of MMP-2, MMP-9, TIMP-1 and TIMP-2 in squamous cell laryngeal carcinoma. Total RNA was extracted from laryngeal samples of healthy subjects and patients of different cancer stages and subjected to RT-PCR analysis for MMP-2 (364 bp), MMP-9 (519 bp), TIMP-1 (534 bp) and TIMP-2 (433 bp). For comparative purposes, RT-PCR analysis of GAPDH (261 bp) was performed and the RT-PCR product ratio of all samples to GAPDH was plotted against cancer stage to obtain a semiquantitative figure of results.

half of the stage III samples (3/6) and in several of the stage IV samples $(2 / 5)$, with the exception of its presence in basement membrane and chondrocytes in all sections examined.

Different results, however, were obtained in the case of TIMPs. TIMP-1 seemed to be present exclusively in stroma and totally absent from epithelium, basement membrane and chondrocytes (Fig. 2, healthy). In addition, it was absent in tumor cells in all stages and its localization was not related to grade. It was overexpressed in normal cells surrounding the tumor. TIMP-2 was identified (Fig. 2, healthy) in the cytoplasm of the epithelial cells, in stroma and sometimes in the chondrocytes. Cancerous samples revealed similar staining to the healthy subjects for TIMP-2; it was absent in tumor cells of almost all stage II (0/5) and stage III (1/6) samples, but was present in tumor cells of all stage IV samples examined (5/5) (Fig. 2, S2).
Expression studies. The expression of gelatinases and their tissue inhibitors was investigated in healthy and cancerous specimens by RT-PCR and characteristic results are shown in Fig. 3. As expected, mRNA of the molecules under study was isolated from all specimens, and a clear stage-related increase of the RT-PCR products was observed. More precisely, the MMP-2/GAPDH RT-PCR product ratio was increased by approximately $40 \%(\mathrm{p}<0.05)$ between healthy and stage II samples, $150 \%(\mathrm{p}<0.01)$ between healthy and stage III samples and $250 \%(\mathrm{p}<0.01)$ between healthy and stage IV samples. The increase was almost similar in both apparently normal and cancerous samples obtained from the patients. A slightly different figure was obtained in the case of MMP-9. The MMP-9/GAPDH RT-PCR product ratio was increased by approximately $15-20 \%$ between healthy and stage II samples, the increase being significant only in the case of cancerous 
Table II. Cumulative results of the immunohistochemical and molecular analyses.

\begin{tabular}{|c|c|c|c|c|}
\hline \multirow[t]{2}{*}{ Stage } & \multirow[t]{2}{*}{ Molecule } & \multicolumn{2}{|c|}{ Molecular analysis } & \multirow{2}{*}{$\begin{array}{c}\text { Immunohistochemistry } \\
\text { Tumor }\end{array}$} \\
\hline & & Normal tissue & Pathologic tissue & \\
\hline \multirow[t]{4}{*}{ II } & MMP-2 & $40 \%$ & $40 \%(\mathrm{p}<0.05)$ & $+++(5 / 5)$ \\
\hline & MMP-9 & - & $20 \%(\mathrm{p}<0.01)$ & $+++(5 / 5)$ \\
\hline & TIMP-1 & $100 \%$ & $100 \%(\mathrm{p}<0.01)$ & $+(1 / 5)$ \\
\hline & TIMP-2 & - & $100 \%(\mathrm{p}<0.01)$ & $-(0 / 5)$ \\
\hline \multirow[t]{4}{*}{ III } & MMP-2 & $150 \%$ & $150 \%(\mathrm{p}<0.01)$ & $+++(4 / 6)$ \\
\hline & MMP-9 & $50 \%$ & $150 \%(\mathrm{p}<0.01)$ & $+++(3 / 6)$ \\
\hline & TIMP-1 & $100 \%$ & $300 \%(\mathrm{p}<0.01)$ & $-(0 / 6)$ \\
\hline & TIMP-2 & $200 \%$ & $1400 \%(\mathrm{p}<0.01)$ & $-/+(1 / 6)$ \\
\hline \multirow[t]{4}{*}{ IV } & MMP-2 & $250 \%$ & $250 \%(\mathrm{p}<0.01)$ & $-/+(1 / 5)$ \\
\hline & MMP-9 & $150 \%$ & $150 \%(\mathrm{p}<0.01)$ & $+/++(2 / 5)$ \\
\hline & TIMP-1 & $100 \%$ & $300 \%(\mathrm{p}<0.01)$ & $-(0 / 5)$ \\
\hline & TIMP-2 & $400 \%$ & $1300 \%(\mathrm{p}<0.01)$ & $+++(5 / 5)$ \\
\hline
\end{tabular}

The net increase of RT-PCR product and the number of positively stained samples in immunohistochemical analysis are indicated.

specimens $(\mathrm{p}<0.01)$. Similarly, that between healthy and stage III patients was increased by approximately $50 \%$ (apparently normal, $\mathrm{p}<0.01$ ) and $150 \%$ (cancerous, $\mathrm{p}<0.01$ ), whereas that between healthy and stage IV patients was increased by approximately $150 \%(\mathrm{p}<0.01)$ in both apparently normal and stage IV stamples, indicating that the expression of MMP-9 differed slightly between stage III and IV cancerous samples.

A more complicated result was obtained in the case of TIMPs (Fig. 3). The TIMP-1/GAPDH RT-PCR product ratio was increased in the apparently normal samples of all cancer stages by approximately $100 \%(\mathrm{p}<0.01)$ as compared with that of healthy samples, whereas in the cancerous samples the increase was approximately $100 \%(\mathrm{p}<0.01)$ in stage II samples and $300 \%(\mathrm{p}<0.01)$ in both stage III and IV samples. In addition, the TIMP-2/GAPDH RT-PCR product ratio was almost the same in the apparently normal samples of stage II patients and was increased by approximately $200 \%$ $(\mathrm{p}<0.01)$ and $400 \%(\mathrm{p}<0.01)$ in the respective stage III and IV samples as compared with that of healthy samples, whereas it was increased by approximately $100 \%(\mathrm{p}<0.01), 1400 \%$ $(\mathrm{p}<0.01)$ and $1300 \%(\mathrm{p}<0.01)$ in the cancerous samples of stages II, III and IV, respectively. The results are indicative of a higher increase of both TIMP-1 and TIMP-2 expression in the laryngeal carcinoma samples, as compared with that of gelatinases.

\section{Discussion}

Remodelling of the extracellular matrix is a critical event during cancer invasion and metastasis, among others (1). It is recognized that this is due to the activity of the members of the MMP family that can degrade extracellular matrix components and thus potentiate local tumor invasion and metastasis (18). However in some tissues of specific nature and composition, such as larynx, additional enzymatic activities should be considered (19) and the model of cancer invasion should be re-examined. Nevertheless, MMPs seem to be the critical enzymes acting in the major extracellular component, collagen, in either a natural or denatured form. MMP-1, MMP-2, MMP-9, and MT-1 MMP are most commonly identified in head and neck tumors and associated with disease progression. In our recent study we observed that gelatinases were greatly associated with disease progression and that the active enzyme to zymogen ratios were increased with cancer stage (2). In the present study we have examined by RT-PCR the expression of gelatinases and we have observed a clear stage-related increase of the RT-PCR product which corresponded with increased transcription rate. The immunohistologic examination suggested their main presence in the cytoplasm of the epithelial cells and in the loose connective tissue. In addition, the number of tumor cells stained positively for gelatinases decreased gradually with cancer stage, leading to the speculation that the role of gelatinases in cancer is expressed very early. Thereafter their removal at the posttranscriptional level should be considered. However, the stromal cells continued their production.

The activity of gelatinases is generally regulated in tissues by TIMPs, mainly TIMP-1 and -2 . TIMP-1 seemed to be exclusively expressed from stromal cells, whereas TIMP-2 was expressed from both stromal and tumor cells. Their expression was also examined and a stage-related increase of the RT-PCR product was observed. In this case, their expression rate according to cancer stages was higher than that observed in the case of gelatinases, in agreement with our previous observation concerning the immunochemical identification of TIMPs, and this might be due to overcoming the increased activation of gelatinases (2). In addition, TIMP expression in the cancerous specimens was found to be approximately double to that observed in the macroscopically normal specimens. This observation might be explained by 
the overall final activity of gelatinases that should be higher in the macroscopically normal specimens as compared with the cancerous to prepare the tissue for cancer invasion. In addition, TIMP-2 should be increased in cancerous specimens to help the activation of MMP-2 and MMP-13. To support the latter hypothesis, the results of the immunohistologic examinations of the specimens should be considered. Indeed, TIMP-2 seemed to be produced not only from stroma cells but also from tumor cells, and especially in the late stages of cancer, in agreement with our previous observations (2). Interestingly, in other studies $(11,12)$ an upregulation of TIMP1 was identified, which is associated with a poor survival, whereas the levels of TIMP-2 were often unchanged between tumors and adjacent normal specimens. However our results show a clear increase of the expression of TIMP-2. This suggests that additional mechanisms may be responsible for the removal of TIMP-2 mRNA from the cells. Since in our recent study, a clear presence of TIMP-2 was observed only in cancerous specimens, in agreement with the results of the present study, it might be speculated that different head and neck tumors behave differently and our observations are related only with squamous cell laryngeal carcinoma.

TIMP-2 increase may, in addition, add to the activation of MMP-2 and -13 through the complexation with MT1-MMP, a critical enzyme controlling proteolytic activity (20). Head and neck tumors were the first in which MT1-MMP was identified (21), and MT1-MMP expression has been reported in $75-100 \%$ of them $(12,22)$. Some preliminary investigations of our group (unpublished data) indicated that MT1-MMP and CD44 expression correlate with distant metastases. In addition, other studies have commonly associated MMP-2 and MMP-9 with lymph node metastasis (13) and poor outcome (14) in laryngeal cancer. It should also be noted that TIMP-2, as a selective inhibitor of MMP-2 may also act to suppress MMP-2 activity in the tumor environment. Nevertheless, in this specific site of the head and neck, different expression and localization of the examined extracellular constituents appeared, suggesting that generalization of conclusions concerning the behaviour of the various head and neck tumors should be avoided.

\section{References}

1. Rosenthal EL and Matrisian LM: Matrix metalloproteinases in head and neck cancers. Head Neck 10: 639-648, 2006.

2. Christopoulos TA, Papageorgakopoulou N, Theocharis DA, Aletras AJ, Tsiganos CP, Papadas TA, Mastronikolis NS, Goumas P and Vynios DH: Diagnostic and classification value of metalloproteinases in squamous human laryngeal carcinoma. Int J Oncol 25: 481-485, 2004.

3. Nelson AR, Fingleton B, Rothenberg ML and Matrisian LM: Matrix metalloproteinases: biologic activity and clinical implications. J Clin Oncol 18: 1135-1149, 2000.

4. Werner JA, Rathcke IO and Mandic R: The role of matrix metalloproteinases in squamous cell carcinomas of the head and neck. Clin Exp Metastasis 19: 275-282, 2002.

5. Itoh Y, Takamura A, Ito N, Maru Y, Sato H, Suenaga N, Aoki T and Seiki M: Homophilic complex formation of MT1-MMP facilitates proMMP-2 activation on the cell surface and promotes tumor cell invasion. EMBO J 20: 4782-4793, 2001.
6. Knauper V, Bailey L, Worley JR, Soloway P, Patterson ML and Murphy G: Cellular activation of proMMP-13 by MT1-MMP depends on the C-terminal domain of MMP-13. FEBS Lett 532: 127-130, 2002.

7. Egeblad $\mathrm{M}$ and Werb Z: New functions for the matrix metalloproteinases in cancer progression. Nat Rev Cancer 2: 161-174, 2002.

8. MacDougall JR and Matrisian LM: Contributions of tumor and stromal matrix metalloproteinases to tumor progression, invasion and metastasis. Cancer Metastasis Rev 14: 351-362, 1995.

9. Shekhar MP, Werdell J, Santner SJ, Pauley RJ and Tait L: Breast stroma plays a dominant regulatory role in breast epithelial growth and differentiation: implications for tumor development and progression. Cancer Res 61: 1320-1326, 2001.

10. Rosenthal EL, McCrory A, Talbert M, Carroll W, Magnuson JS and Peters GE: Expression of proteolytic enzymes in head and neck cancer-associated fibroblasts. Arch Otolaryngol Head Neck Surg 130: 943-947, 2004.

11. O-Charoenrat P, Rhys-Evans PH and Eccles SA: Expression of matrix metalloproteinases and their inhibitors correlates with invasion and metastasis in squamous cell carcinoma of the head and neck. Arch Otolaryngol Head Neck Surg 127: 813-820, 2001.

12. Kurahara S, Shinohara M, Ikebe T, Nakamura S, Beppu M, Hiraki A, Takeuchi H and Shirasuna K: Expression of MMPs, MT-MMP, and TIMPs in squamous cell carcinoma of the oral cavity: Correlations with tumor invasion and metastasis. Head Neck 21: 627-638, 1999.

13. Xie M, Sun Y and Li Y: Expression of matrix metalloproteinases in supraglottic carcinoma and its clinical implication for estimating lymph node metastases. Laryngoscope 114: 2243-2248, 2004.

14. Katayama A, Bandoh N, Kishibe K, Takahara M, Ogino T, Nonaka S and Harabuchi Y: Expressions of matrix metalloproteinases in early-stage oral squamous cell carcinoma as predictive indicators for tumor metastases and prognosis. Clin Cancer Res 10: 634-640, 2004.

15. Ruokolainen H, Pääkkö P and Turpeenniemi-Hujanen T: Expression of matrix metalloproteinase-9 in head and neck squamous cell carcinoma: a potential marker for prognosis. Clin Cancer Res 10: 3110-3116, 2004.

16. Ruokolainen H, Pääkkö P and Turpeenniemi-Hujanen T: Tissue inhibitor of matrix metalloproteinase-1 is prognostic in head and neck squamous cell carcinoma - comparison of the circulating and tissue immunoreactive protein. Clin Cancer Res 11: 3257-3264, 2005.

17. Ruokolainen H, Pääkkö P and Turpeenniemi-Hujanen T: Tissue and circulating immunoreactive protein for MMP-2 and TIMP-2 in head and neck squamous cell carcinoma - tissue immunoreactivity predicts aggressive clinical course. Mod Pathol 19: 208-217, 2006.

18. Liotta LA: Tumor invasion and metastases - role of the extracellular matrix: Rhoads Memorial Award lecture. Cancer Res 46: $1-7,1986$

19. Christopoulos TA, Papageorgakopoulou N, Theocharis DA, Mastronikolis NS, Papadas TA and Vynios DH: Hyaluronidase and CD44 hyaluronan receptor expression in squamous cell laryngeal carcinoma. Biochim Biophys Acta 1760: 1039-1045, 2006.

20. Sato H, Takino T, Okada Y, Cao J, Shinagawa A, Yamamoto E and Seiki M: A matrix metalloproteinase expressed on the surface of invasive tumour cells. Nature 370: 61-65, 1994.

21. Okada A, Bellocq JP, Rouyer N, Chenard MP, Rio MC, Chambon P and Basset P: Membrane-type matrix metalloproteinase (MT-MMP) gene is expressed in stromal cells of human colon, breast, and head and neck carcinomas. Proc Natl Acad Sci USA 92: 2730-2734, 1995.

22. Birkedal-Hansen B, Pavelic ZP, Gluckman JL, Stambrook P, Li YQ and Stetler-Stevenson WG: MMP and TIMP gene expression in head and neck squamous cell carcinomas and adjacent tissues. Oral Dis 6: 376-382, 2000. 